\title{
KNOCK CHARACTERISTICS ANALYSIS OF A SUPERCHARGED SPARK IGNITION ENGINE USING THREE GRADES OF FUELS
}

\author{
D. C. Uguru-Okorie ${ }^{1,}{ }^{*}$, A. A. Dare ${ }^{2}$ and A. A. Burluka ${ }^{3}$ \\ 1DEPARTMENT OF MECHANICAL ENGINEERING, LANDMARK UNIVERSITY, OMU-ARAN, KWARA STATE, NIGERIA \\ 2DEPARTMENT OF MECHANICAL ENGINEERING, UNIVERSITY OF IBADAN, IBADAN, OYO STATE, NIGERIA \\ 3DEPT. OF MECHANICAL \& CONSTRUCTION ENG'G, NORTHUMBRIA UNIV., NEWCASTLE-UPON-TYNE NE1 8ST, UK \\ E-mail addresses: ${ }^{1}$ danchukus@yahoo.com, ${ }^{2}$ ademola_dare@yahoo.com, \\ 3 alexey.burluka@northumbria.ac.uk
}

\begin{abstract}
The power output of a spark ignition engine could be improved by boosting the intake pressure and compression ratio; however the applications of these are limited by knock in engines. This study examined the knocking behaviours of three commercially available fuels for spark ignition engines operated at engine intake pressures of 1.6 and 2.0 bar. The pressure data for the fuels tested were grouped into three: the fast cycle, medium cycle and slow cycles. Knock intensities from the pressure data were processed with Fast Fourier Transform (FFT) and band pass filtering techniques. The results showed that the knocking cycles occurred only in the fast and medium cycles. These results supported the view that auto-ignition of end-gases was due to compression from the high speed propagating flames. FTiR spectrums showed that the presence of aromatics was responsible for the better anti-knock quality exhibited by E5 and ULG 98 over PRF 95.
\end{abstract}

Keywords: End gas, Fuel, FTiR, Knock, Spark Ignition Engine, Supercharging, Pressure.

\section{INTRODUCTION}

The power output of a spark ignition engine could be improved by boosting the intake pressure and compression ratio; however the applications of these are limited by knock in engines $[1,2]$. This limitation is being addressed by the development of new fuels and operating conditions for spark ignition engines. Understanding the knock behaviours of these fuels at different engine conditions is important in the design and manufacturing of spark ignition engines with improved performance. Understanding factors influencing knock in spark ignition engines will help designers understand how to manage knock in engines.

Various designs over the years have been introduced in internal combustion engines with the aim of improving its performance. They include the redesigning of its inlet manifold to enhance turbulence, the redesigning of the combustion chamber to increase swirl and tumble $[3,4]$, positioning of the spark plugs for short flame travel and injectors for better fuel mixing etc [5]. All these design factors have all been geared towards improving combustion efficiency, engine power output and a reduction in the amount of expelled products of incomplete combustion [6]. In addition to this, increasing the intake pressure of an engine by supercharging or turbocharging has also been employed to improve the power output of internal combustion engines but its application in SI engines has been limited by engine knock. In response to this, various types of fuels (conventional and bio-derived) have been developed and tested over the years to run on both naturally aspirated and supercharged or turbocharged $[7,8]$ spark ignition (SI) engines without knock occurring.

Supercharged engines operate at intake pressures below 1.6 bar, presently [9 - 11] and as the drive to further downsize engines continues, there will be need for supercharging of these engines to higher degrees. The selection and use of suitable fuels, which are commercially available, in these heavily supercharged engines will be required. Understanding the knock behaviours of these fuels in heavily supercharged or turbocharged engines will help vehicle designers and manufacturers make appropriate decisions on engine designs and fuel selection.

\section{FUEL ANTI-KNOCK RATING AND ABNORMAL COMBUSTION}

Fuels for spark ignition engines are rated by RON (Research Octane Number) and MON (Motor Octane Number) but over the years, research has shown that various fuels at various supercharged conditions, behave differently at varying engine conditions [12]. Knowing that increasing the intake pressure of an engine is a 
means to achieve better engine power output and realizing that this makes SI engines prone to knock, there is need to test some selected fuels available for SI engines at their knocking regimes with the aim of understanding the factors behind their knocking behaviours.

Combustion in a spark ignition engine is termed normal if it is initiated by a timed spark plug and the air-fuel mixture (charge) is consumed solely by the propagating flame front which originates from the discharged spark and completely moves across the combustion chamber $[5,13]$. Pressure oscillations from combusting charge, which results from abnormal combustion; which could be detrimental to the engine components, does not occur in normal combustion. Abnormal combustion in spark ignition engines majorly occur as knock and surface ignition. While all abnormal combustion in spark ignition engines do not lead to knock (as seen in non-knocking surface ignition), most do [5, 14].

Knock being a form of abnormal combustion, can be defined as a phenomenon which leads to high pressure oscillation in the combustion chamber of an engine as a result of the spontaneous auto-ignition of end-gases ahead of the propagating flame in the combustion engine $[1,5,15$ and 16]. The auto-ignition of these end-gases occur as a result of an increase in temperature experienced by the end gases, which results from the compression exerted by the propagating flame and heat transfer, through radiation from the propagating flame.

Surface ignition is the ignition of air-fuel mixture by hot spots in the combustion chamber of the engine, which could result from glowing combustion deposits, over heated valves or spark plugs or by other means other than a timed spark plug discharge. Surface ignition can take place before or after the introduction of spark. Such ignition before and after the introduction of spark are known as pre-ignition and post-ignition respectively [5]. The occurrence of knock in engines is explained by different theories. The detonation theory assumes that high shockwave generated by the propagating flame due to its supersonic velocity of propagation causes the autoignition of the end-gas while the auto-ignition theory states that the auto-ignition of the end-gas is as a result of the increase in temperature and pressure in the end gas region [14, 17]. Auto-ignition of end-gas was further explained by Pan and Sheppard [18] as being multiple hot spots causing engine knock as opposed to a single hot spot. They found out that the first hot spot modifies the temperature gradient around the second hot spot (the second hot spot having a lower temperature than the first) and it continues in this trend. The second hot spot, some of the time, reacts more slowly than the first but could react more violently developing a detonation type of reaction which leads to engine knock.

Several methods are employed in the detection and measurement of knock in engines [5, 19 - 21]. Lee [19] suggested that knock analysis from measured cylinder pressure data gives the most accurate knock processing information and Brunt [20] used pressure data for knock analysis.

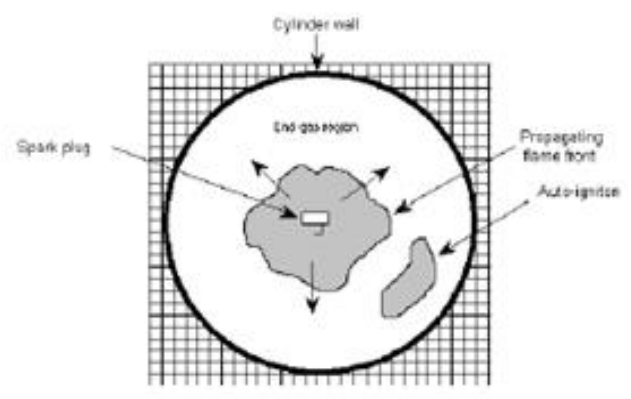

Figure 1: A diagram of a propagating flame with an autoignited end-gas [17]

\section{EXPERIMENTAL SETUP AND ENGINE OPERATING CONDITIONS}

The setup for the experiment consists of an engine with specifications as shown in Table 1; a variable speed dynamometer and various test and control equipment. The photographs of the test engine setup and the FTIR spectrometer are shown in Fig. 2. All the experiments were run at an engine speed of 750 revolutions per minute (rpm), at stoichiometric condition, intake temperature of $50^{\circ} \mathrm{C}(323 \mathrm{~K})$ and at inlet pressures of 1.6 and 2.0 bar. The intake air for the engine was from the laboratory compressed air system as used by [7] at the basement of the Leeds University thermo-Fluids Lab. The pressure of the air supplied to the engine was regulated by the airflow meter controlled with a LabView script. Three (3) fuels; E5 fuel (95\% gasoline and 5\% ethanol, RON 97), ULG 98 (Unleaded Gasoline, RON 98) and PRF 95 (RON 95, Primary Reference Fuel) were tested at the various knock regimes and an FTiR Spectrometer was used to determine the functional groups present in the fuel.

\subsection{Experimental Procedure}

The experiment involved the test of three (3) fuels; E5 fuel (95\% gasoline and 5\% ethanol, RON 97), ULG 98 (Unleaded Gasoline, RON 98) and PRF 95 (RON 95) in a two-stroke, single cylinder, spark ignition engine. Experimental pressure data were collected and processed at intake pressures of 1.6 and 2.0 bar. The comparison of PRF 95 with the other two fuels tested was limited to knock boundary determination and FTiR analysis. Test with PRF 95 was not carried out beyond $8 \mathrm{bTDC}$ as a result of heavy knock observed with ignition advance in the research engine. The engine specifications are presented in Table 1 and Figure 2 shows some parts of the experimental setup. The fuels tested were fuels commercially available for spark ignition (SI) engines. 

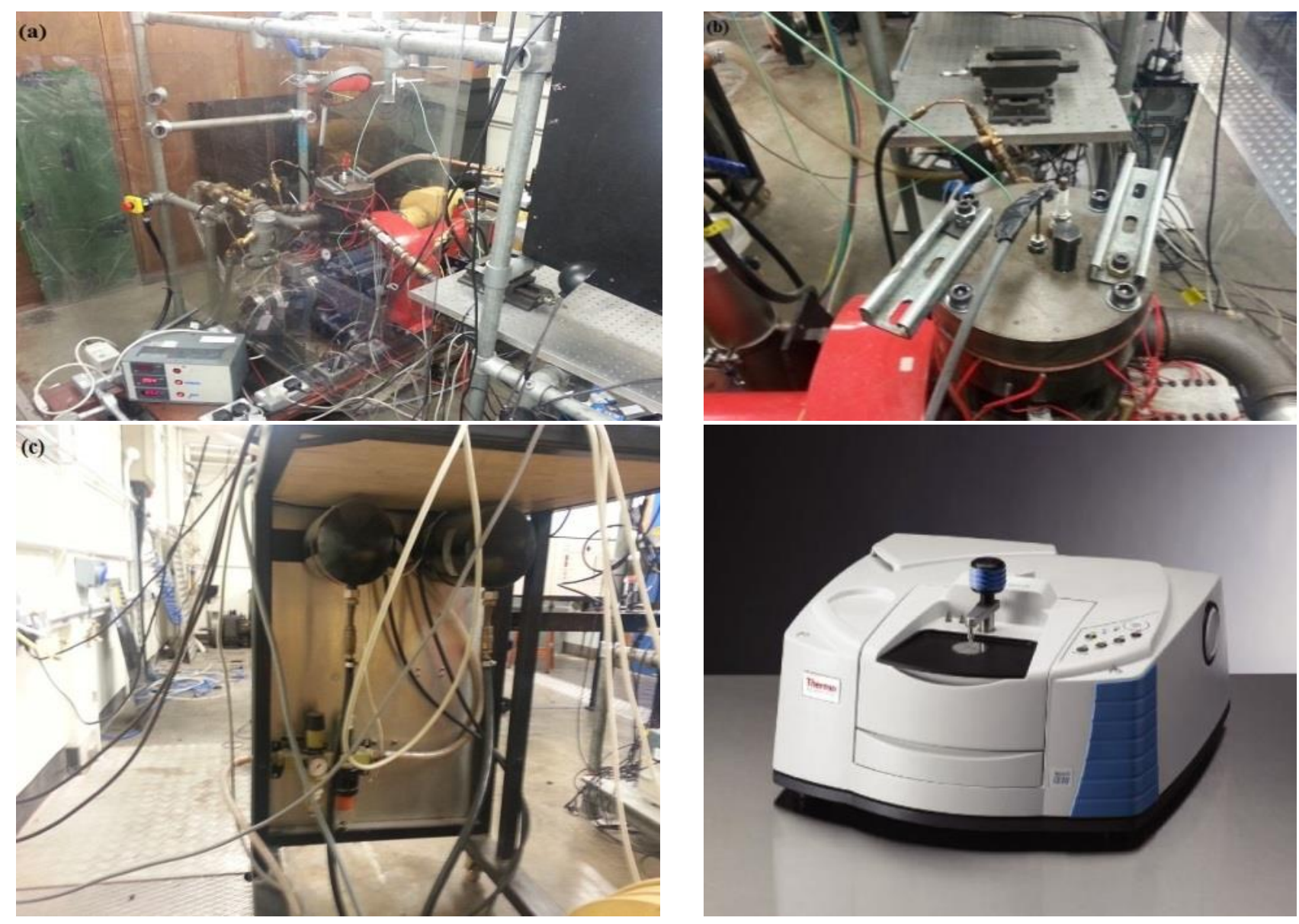

Figure 2: Experimental Setup (a) Engine test rig, (b) Engine top cylinder, (c) Surge tank and (d) FTiR spectrometer

Table 1: Engine Specification

\begin{tabular}{ll}
\hline Bore & $80 \mathrm{~mm}$ \\
\hline Stroke/Effective Stroke & $110 \mathrm{~mm} / 65.9 \mathrm{~mm}$ \\
Clearance Height & $8 \mathrm{~mm}$ \\
Compression ratio & $10.4: 1$ \\
Inlet Port Open/Close & $107.8^{\circ}$ (aTDC/bTDC) \\
Exhaust Port Open/Close & $127^{\circ}(\mathrm{aTDC} / \mathrm{bTDC})$ \\
Engine Speed & $750 \mathrm{rpm}$ \\
\hline
\end{tabular}

The spark ignition engine used for the experiment, which is known as the Leeds University Ported Optical Engine (LUPOE), had the optically accessible top cylinder replaced with a flat disc top cylinder head of the same dimension, as shown in Figure 2(b). The tests were carried out with air-fuel mixture of equivalence ratio 1.0. This was achieved for all intake pressure conditions by adjusting the flow of fuel to suit the required air-fuel ratio. The engine speed was maintained at $750 \mathrm{rpm}$ all through the experiment with a dynamometer connected to the engine. The engine intake pressure setting was done with a LabView script which controlled the air metering of the airflow meter. The in-cylinder pressures were measured by a Kistler piezoelectric pressure transducer (Type 4162619) and the signals from the crankshaft encoder which transmitted at every $0.2 \mathrm{CA}$, made it possible to resolve the measured in-cylinder pressure with the engine crank angle. The data acquisition system was controlled by a LabView script written which acquired pressure data at a sampling rate of $200 \mathrm{kHz}$. The obtained pressure data was then processed with a MATLAB script. The temperature of the fresh charge was maintained at a temperature of $50{ }^{\circ} \mathrm{C}$ with electric heater which had its heating elements connected to the engine's inlet manifolds and the cylinder wall. Fluctuation in the intake pressure from cycle to cycle was minimized with installed surge tanks upstream of the intake manifolds. A skip-firing between cycles was employed to ensure the elimination of residues of exhaust gases in the cylinder. The exhaust gas extractor was switched on to enhance the expulsion of exhaust gases.

In each of the test condition, which was done at spark timings in the engine's knocking region, 50 firing pressure cycles were obtained and processed. The experimental pressure data collected in the engine knocking region were taken at different intake pressures (1.6 and 2.0 bar) for each of the fuels tested. The spark timing was advanced by a step of $4{ }^{\circ} \mathrm{CA}$ at various intake pressures until engine knocking conditions were 
detected. The spark timing was then retarded by a step of $1^{\circ} \mathrm{CA}$ from the spark timing knocking was detected, to determine the spark timing of knock onset (knock boundary) at various engine conditions. The high bypass filtering was then used with a cut-off of frequency of $5 \mathrm{KHz}$ and the filtering of the processed knocking cycles was done with the MATLAB's filtfilt command. This MATLAB command was used because it has been previously tested and found to prevent phase shift during filtering which gives accuracy in the determination of the crank angle of knock onset [15].

The firing cycles were classed into three groups depending on the peak pressure generated from the each of the cycles. The firing cycles were grouped into the Fast, Medium and Slow cycles. The fast cycles $P_{\text {Fast }}$ were cycles with pressures greater than $P_{\text {mean }}+P_{S T D}$, The medium cycle, $P_{\text {medium }}$ were the pressures within the range: $P_{\text {mean }}+P_{S T D} \geq P_{\text {medium }} \geq P_{\text {mean }} . P_{S T D}$ and the slow cycle $P_{\text {slow }}$ are pressure below $P_{\text {mean }}-P_{S T D D}$. The groupings are as follows:

$$
\begin{aligned}
P_{\text {fast }} & >\left(P_{\text {mean }}+P_{S T D}\right) \\
\left(P_{\text {mean }}+P_{S T D}\right) & \geq P_{\text {medium }} \geq\left(P_{\text {mean }}-P_{S T D}\right) \\
P_{\text {slow }} & <\left(P_{\text {mean }}-P_{S T D}\right)
\end{aligned}
$$

The Mean Cycle Peak Pressure $P_{\text {mean }}=\cdots \frac{1}{N} \sum_{i=1}^{N} P_{\max }$

In (1), $N$ is the number of firing cycles considered for an engine operating condition and $P_{\max }$ is the peak pressure of each of the firing cycles considered. $P_{\text {mean }}$ and $P_{S T D}$ are the mean value and standard deviation of the in-cylinder peak pressures for the number (N) of firing cycles considered for an engine operating condition respectively.

FTiR spectra were obtained for the various fuels tested with the aim of determining the functional groups present and how they affect the behaviour of the fuels tested.

\section{RESULTS}

\subsection{Knock Boundaries of the Various Fuels at 1.6 bar and 2.0 bar Inlet Pressures}

Knock boundary is the engine spark timing at which, if advanced beyond, knocking of engine cycles occurs in a spark ignition engine. The results presented in Figure 3 show the knock boundaries of E5, ULG 98 and PRF 95 at engine intake pressures of $1.6 \mathrm{bar}$ and for E5 and ULG 98 at engine intake pressure of 2.0 bar.

E5 exhibited the best anti knock quality with knock boundaries of 13 and 12 bTDC (Before Top Dead Centre) at engine intake pressures of 1.6 and 2.0 bar respectively. This was followed by ULG 98 with knock boundaries at 12 and $11 \mathrm{bTDC}$ at engine intake pressures of 1.6 and 2.0 bar respectively. PRF 95, at 1.6 bar intake pressure had its knock boundary at 7 bTDC. The result obtained show that E5 fuel was the most suitable fuel for supercharged
SI engines followed closely by ULG 98 while PRF 95 was the least.

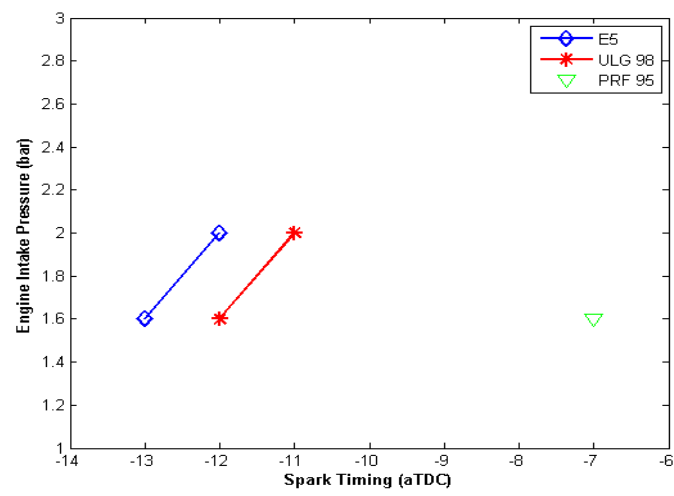

Figure 3: Knock boundaries for E5, ULG 98 and PRF 95 at intake pressures of 1.6 and 2.0 bar.

\subsection{Effect of Fast and Medium Cycles on Knock Intensities}

From the results obtained, the fast knocking cycles, for the two fuels, E5 and ULG 98 tested, were observed to have higher knock intensity compared to the knock intensities of the medium knocking cycles. The graphs are shown in Figure 4.

\subsection{Effect of Fast, Medium and Slow Cycles on Knock Occurrence}

From the processed experimental pressure data for E5 and ULG 98 tested, at an engine loads of 1.6 and 2.0 bar, the results obtained as shown in Figures 4 and 5, show that engine knock (in-cylinder pressure oscillations) occurred only in the fast and medium cycles. No knocking cycle was observed in the slow cycles.

Knocking cycles of the engine when run with the two fuels: E5 and ULG 98, was observed in the fast and medium cycles only. This suggests that the knock theory that associates the cause of auto-ignition of end gas with shock-wave generated by the propagating flame has a higher possibility of being the source of auto-ignition in the engine. The non-knocking cycles observed in the slow cycles supports this claim too.

\subsection{Comparison of the Crank Angles at Knock Onset and that of Maximum Knock Intensity}

The crank angles at which knock onset and maximum knock intensity occurred were determined for E5 and ULG 98 fuels at the various engine conditions, as shown in the Figures 6 and 7.

From the results obtained from the knocking cycles, the crank angle at knock onset and the crank angle where the highest knock intensity in the cycle were observed, occurred at the same crank angle with a few of the cycles having their maximum knock intensity occurring at later crank angles after knock onset. This was observed in the fuels, E5 and ULG 98, at the various engine knock test conditions. 
(a)

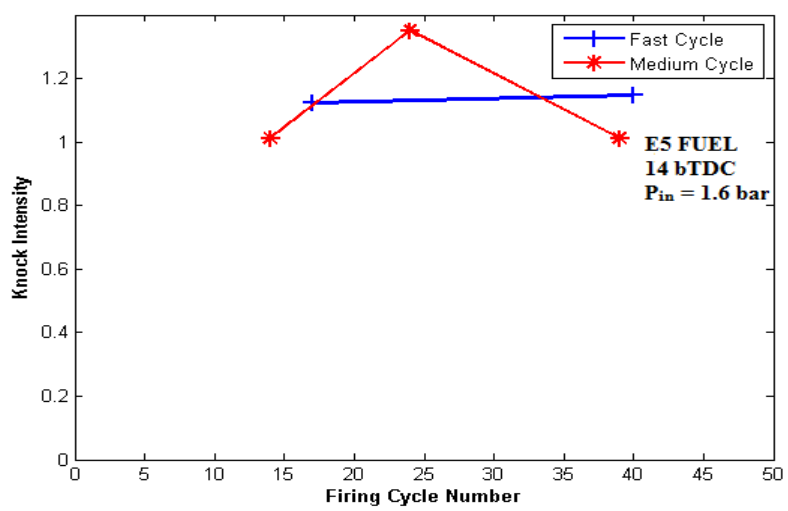

(c)

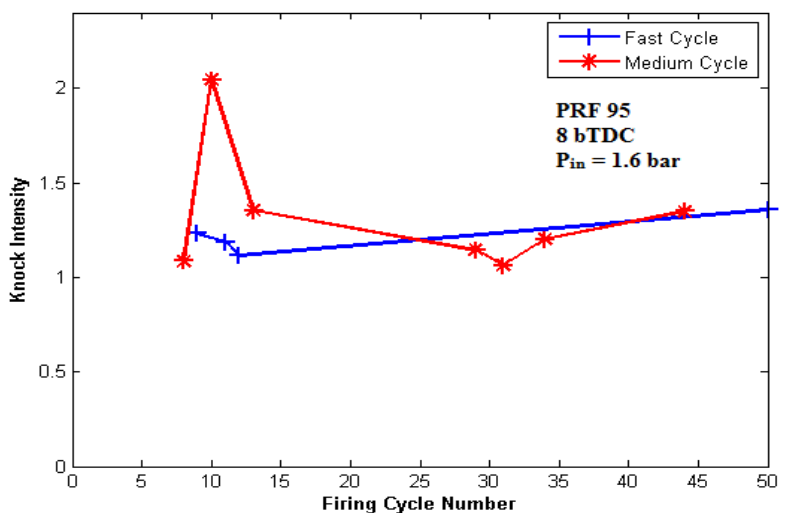

(e)

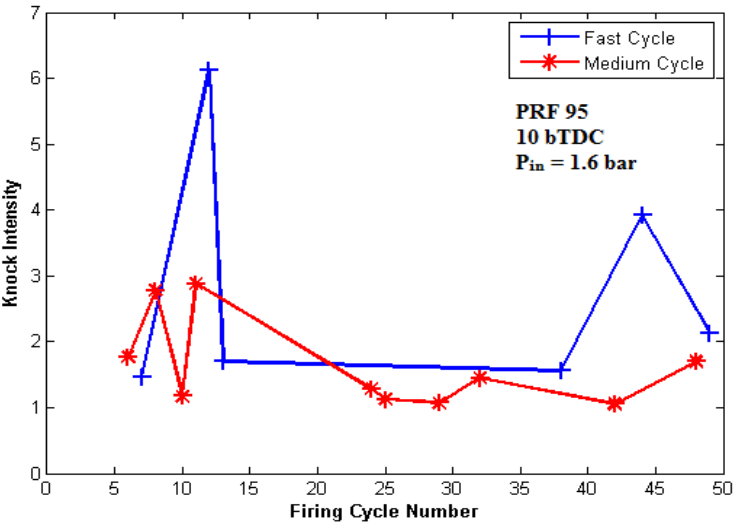

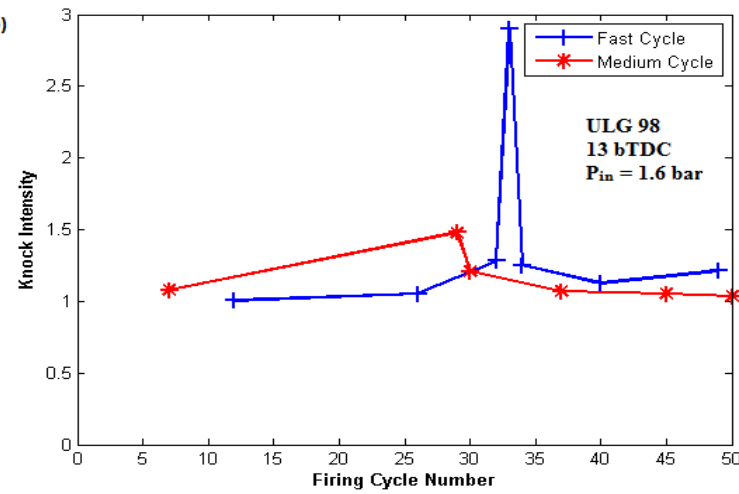

(d)
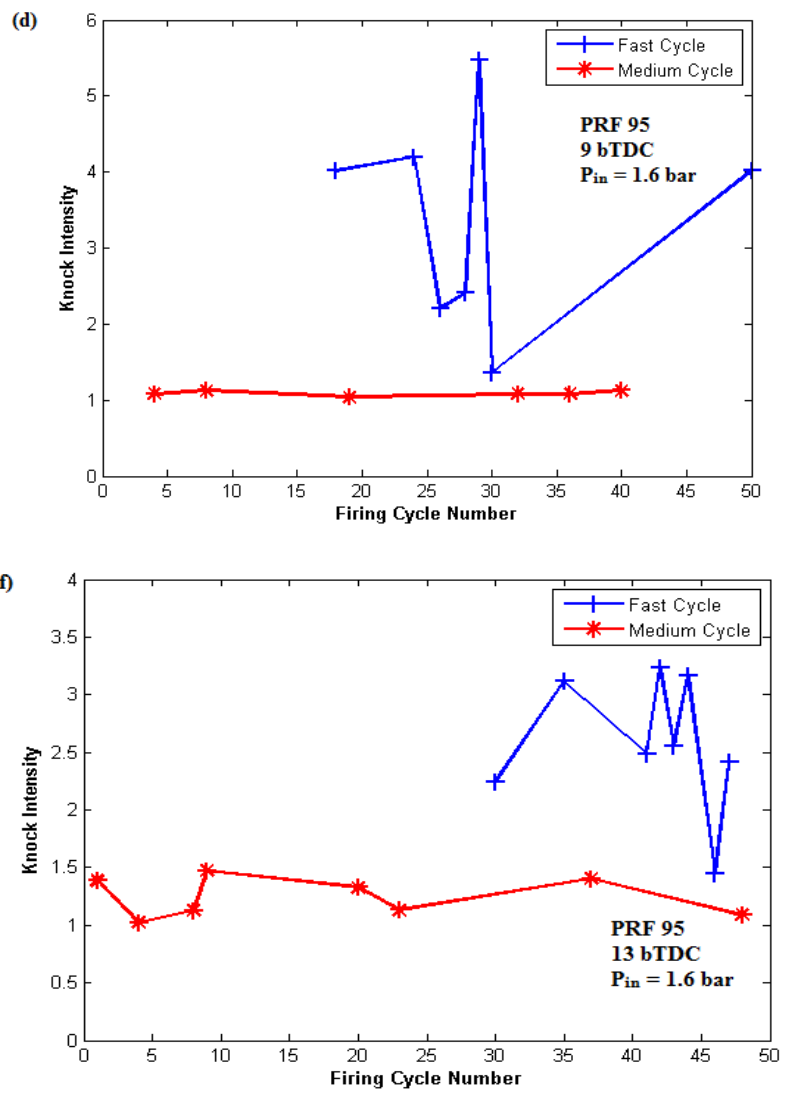

Figure 4: A graph of the Knock Intensity for the fast and medium knocking cycles at inlet pressure of 1.6 bar for (a) E5 at 14 bTDC (b) ULG 98 at 13 bTDC (c) PRF 95 at 8 bTDC (d) PRF 95 at 9 bTDC (e) PRF 95 at 10 bTDC (f) PRF 95 at 13 $b T D C$
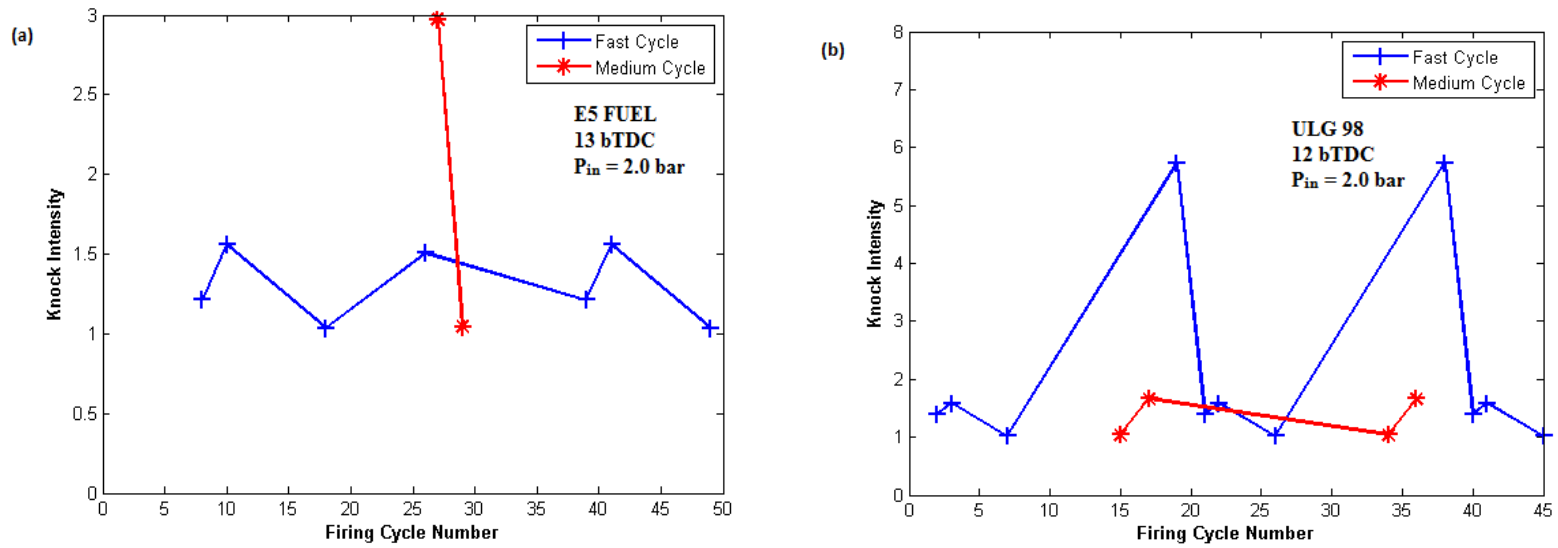

Figure 5: A graph of the knock intensity for the fast and medium knocking cycles for (a) E5 and (b) ULG 98 at intake pressure 2.0 bar 
(a)

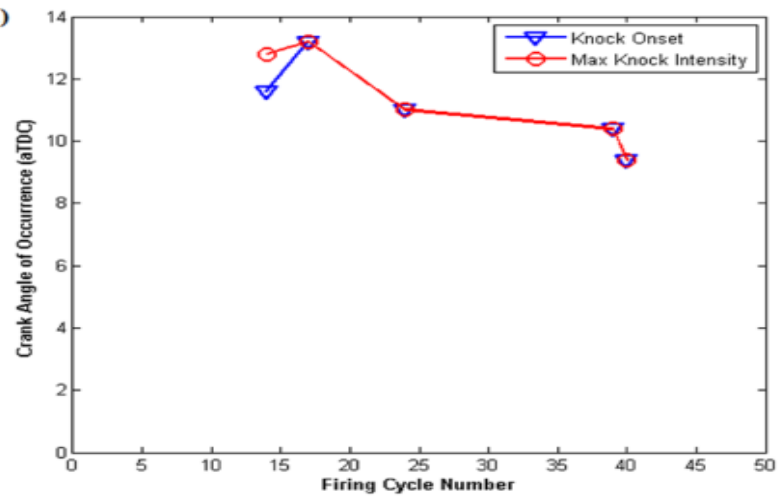

(c)

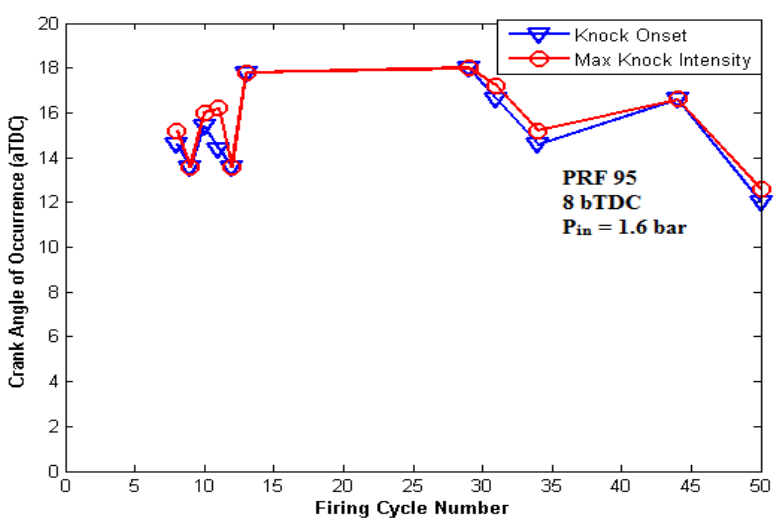

(e)

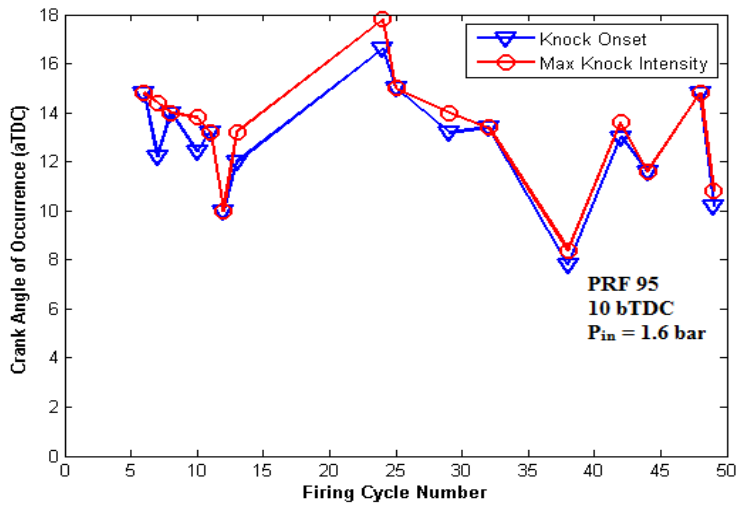

(b)

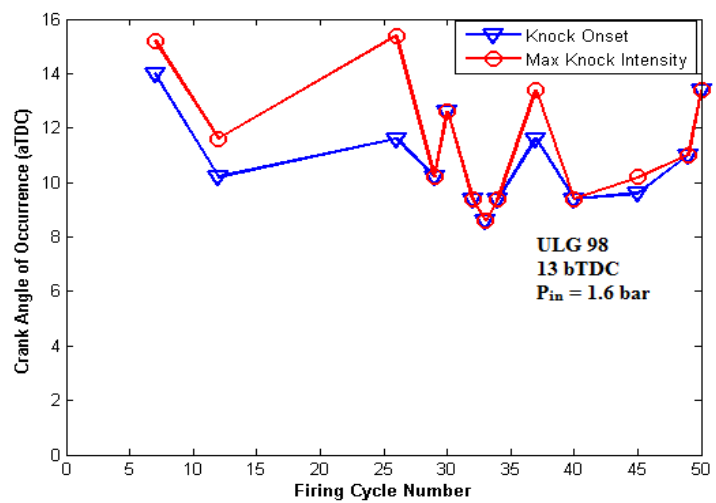

(d)

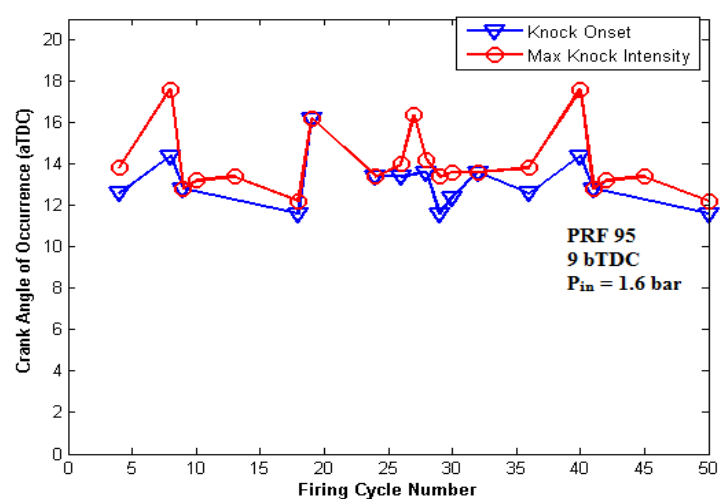

(f)

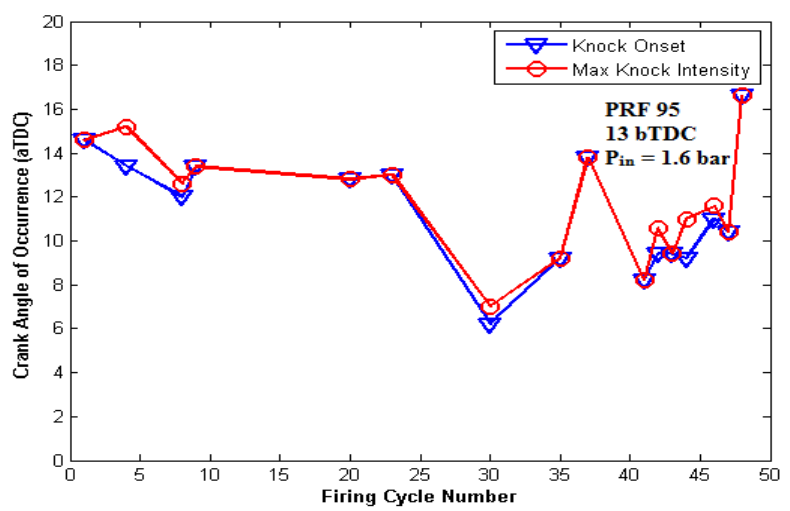

Figure 6: Crank Angle of Occurrence of Knock Onset and Maximum Knock Intensity at Intake Pressure 1.6 bar for (a) E5 at 14 bTDC (b) ULG 98 at 13 bTDC (c) PRF 95 at 8 bTDC (d) PRF 95 at 9 bTDC (e) PRF 95 at 10 bTDC (f) PRF 95 at 13 bTDC

(a)

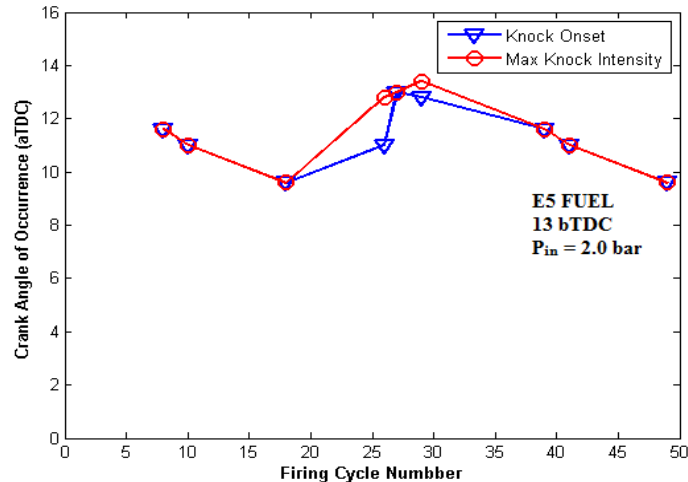

(b)

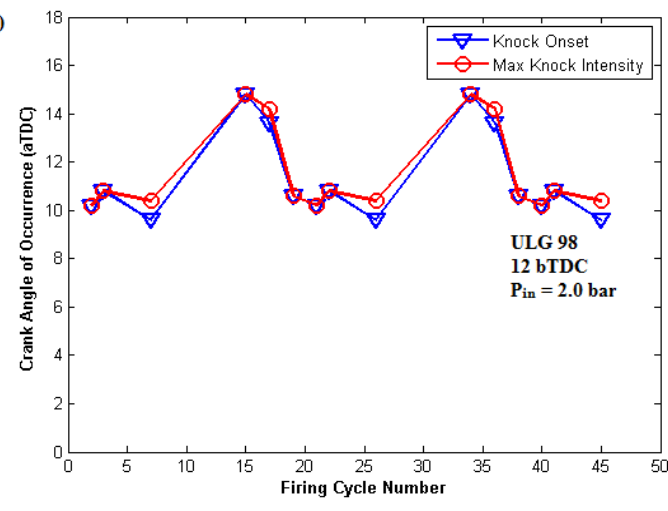

Figure 7: Crank Angle of Occurrence of Knock Onset and Maximum Knock Intensity at Intake Pressure 2.0 bar for (a) E5 at 13 bTDC (b) ULG 98 at 12 bTDC 


\subsection{Crank Angles of Knock Onset Occurrence in Fast and Medium Cycles}

The crank angle at knock onset in the fast knocking cycles occurred at earlier crank angles compared to the medium knocking cycles and similar observation was made at the crank angles where the fast and medium cycle peak pressures occurred. The results are shown in Figures 8 and 9 respectively.

The earlier onset of knock in the fast cycle could be attributed to the faster propagating flame compression effect on the auto-ignition of the end-gas compared to the medium cycles in which the knock onset occurs at a later crank angle.

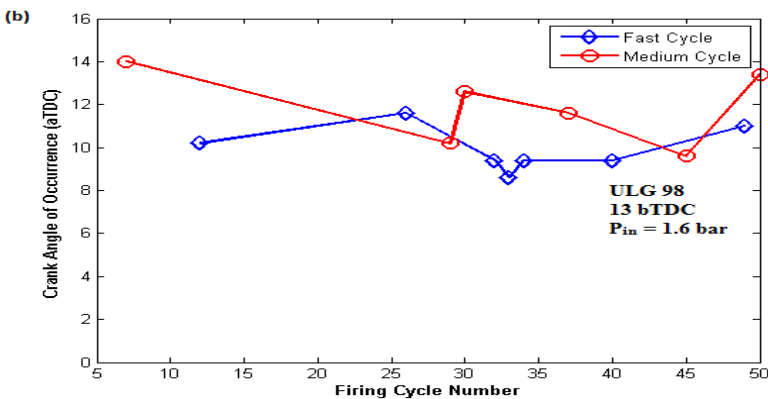

(d)
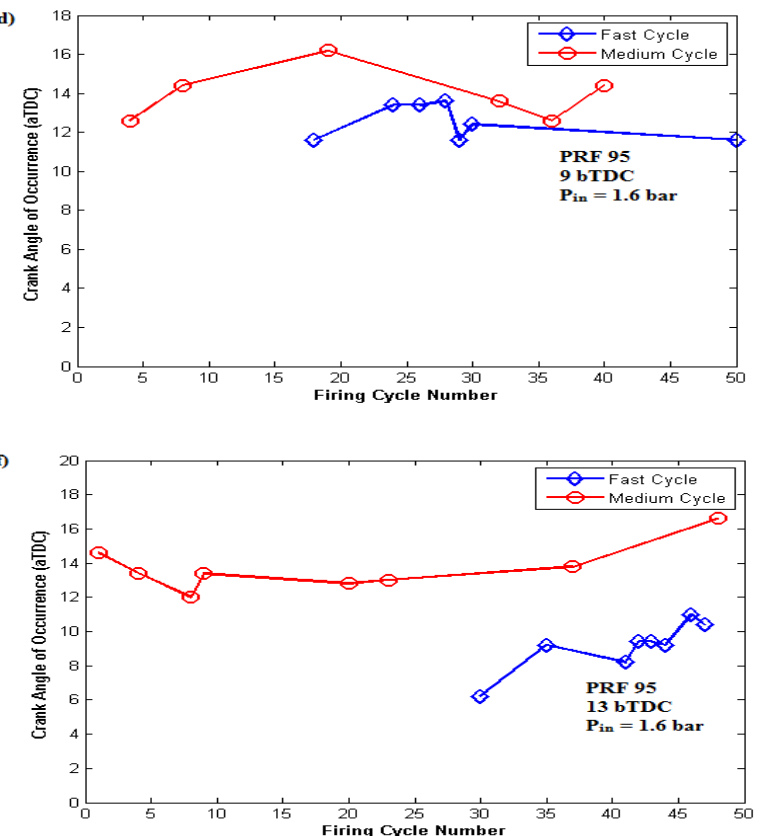

Figure 8: A graph of the crank angle for knock onset on the fast and medium knocking cycles at intake pressure 1.6 bar for (a) E5 at 14bTDC (b) ULG 98 at $13 b T D C$ (c)PRF95 at 8bTDC (d) PRF95 at $9 b T D C$ (e) PRF 95 at $10 b T D C$ and (f) PRF95 at $13 b T D C$

(a)

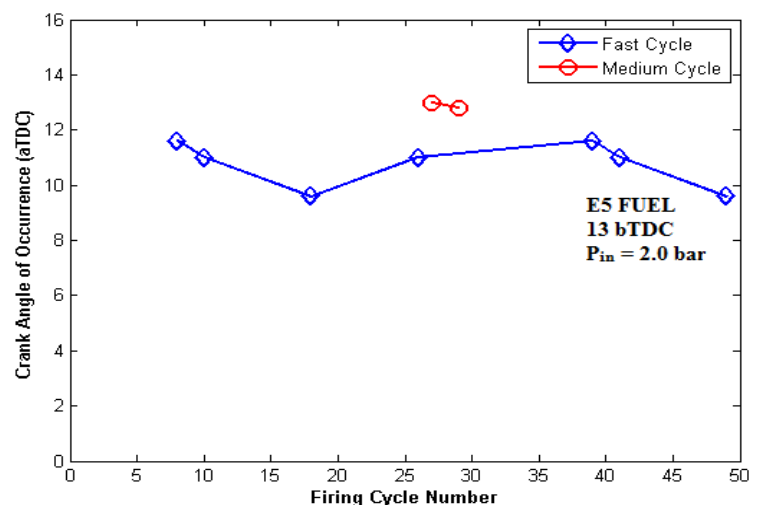

(b)

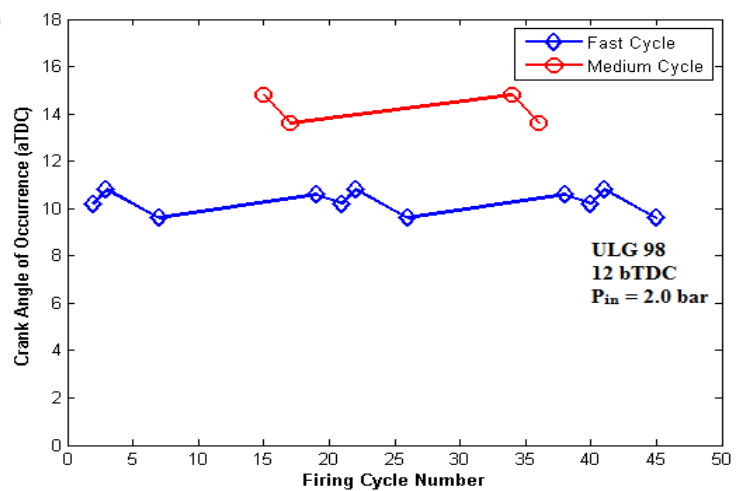

Figure 9: A graph of the crank angle for knock onset on the fast and medium knocking cycles for (a) E5 and (b) ULG 98 at intake pressure 2.0 bar 


\subsection{FTiR Spectroscopy on the Fuels}

FTiR spectroscopy on the three fuels tested was carried out to determine the effect of the functional groups present in the fuels, on its knock behaviour [22-24].

The spectrum obtained from each of the fuels as shown in Figure 10 were compared. Similar functional groups were observed in E5 and ULG98 fuels which had similar anti-knocking behaviour as seen in Figure 10(a) while there was noticeable difference in the fuel with the least anti-knocking quality (PRF95) as shown in Figure 10(b) and (c). A comparison of the spectrum of E5 and ULG 98; E5 and PRF 95; ULG 98 and PRF95 and E5 fuel, ULG 98 and PRF 95 were done respectively as shown in figures 10 (a-d). PRF 95 was seen to have higher compounds of branched chain aliphatic as seen in the methyl $-\mathrm{CH}_{3}$ functional group intensity $\left(2953 \mathrm{~cm}^{-1}\right.$ and $\left.2872 \mathrm{~cm}^{-1}\right)$, compared to E5 and ULG 98. E5 fuel was observed to have the least intensity of methyl $-\mathrm{CH}_{3}$ implying it had the least content of the branched chain aliphatic. E5 and ULG 98 were observed to have the most common functional groups with the intensities varying from one fuel to the other. Obvious functional groups missing in PRF 95, which are present in E5 and ULG 98,are the aromatic ring functional groups $\left(900-670 \mathrm{~cm}^{-1} ; 1615-\right.$ $1580 \mathrm{~cm}^{-1}$ and $\left.3010-3100 \mathrm{~cm}^{-1}\right)$ as shown in the circled points on the graph in Figure 10(d). E5 compared to ULG 98 had the highest content of the aromatic ring functional groups and was also observed to exhibit the best anti-knock behaviour in all the knock experiments carried out.
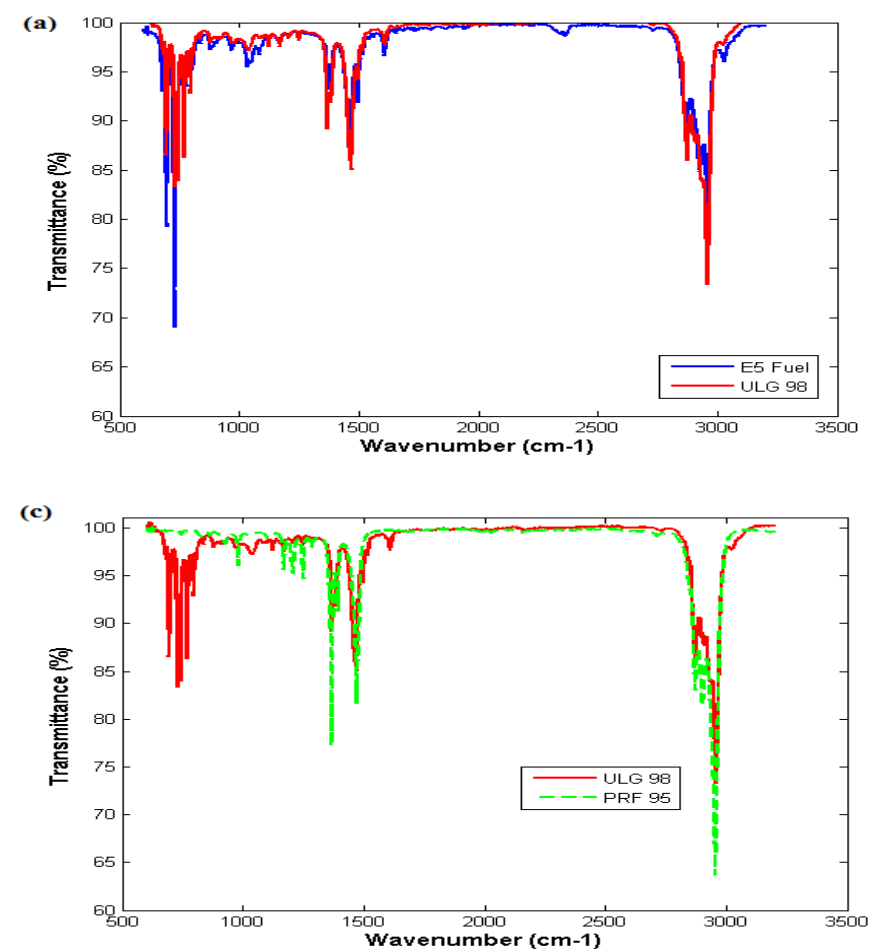

Figure 10: Comparison of FTiR spectrum for (a) E5 fuel and ULG 98 (b) E5 fuel and PRF 95 (c) ULG 98 and PRF 95 (d)

$\begin{array}{r}\text { E5 fuel, ULG } 98 \text { and PRF } 95 \\ \hline\end{array}$

\section{CONCLUSION}

Post-ignition knock occurred at various engine test conditions, with all the fuels tested. The knocking cycles were only observed in the fast and medium cycles and none occurred in the slow cycles. Knocking fast cycles, had the crank angles at which knock onset and peak pressure occurred, closer to the Top Dead Center (TDC) compared to that of the knocking medium cycles. The observations made, show that knock in the fast and medium cycles were as a result of compression of end gas from fast propagating flames. The occurrence of the peak pressure at crank angle closer to TDC for the fast cycles compared to the medium, suggests faster mass burning rate for the fast cycles compared to the medium and slow cycles. Higher knock intensities observed at the onset of knock, followed by lower knock intensities in the knocking cycles, suggests the auto-ignition of the region of the end-gas with higher energy level with subsequent auto-ignition of smaller end gas patches. Higher knock intensities observed in the fast cycles when compared to the medium cycles could have been influenced by higher flame compression of the end gas by faster propagating flames. E5 fuel exhibited the best anti-knock behaviour while PRF 95 performed least. This could be attributed to the large constituent of aromatics in E5 fuel and its absence in PRF 95. E5 and ULG 98 fuel were observed to be the most suitable amongst the fuels tested for heavily supercharged SI engines.
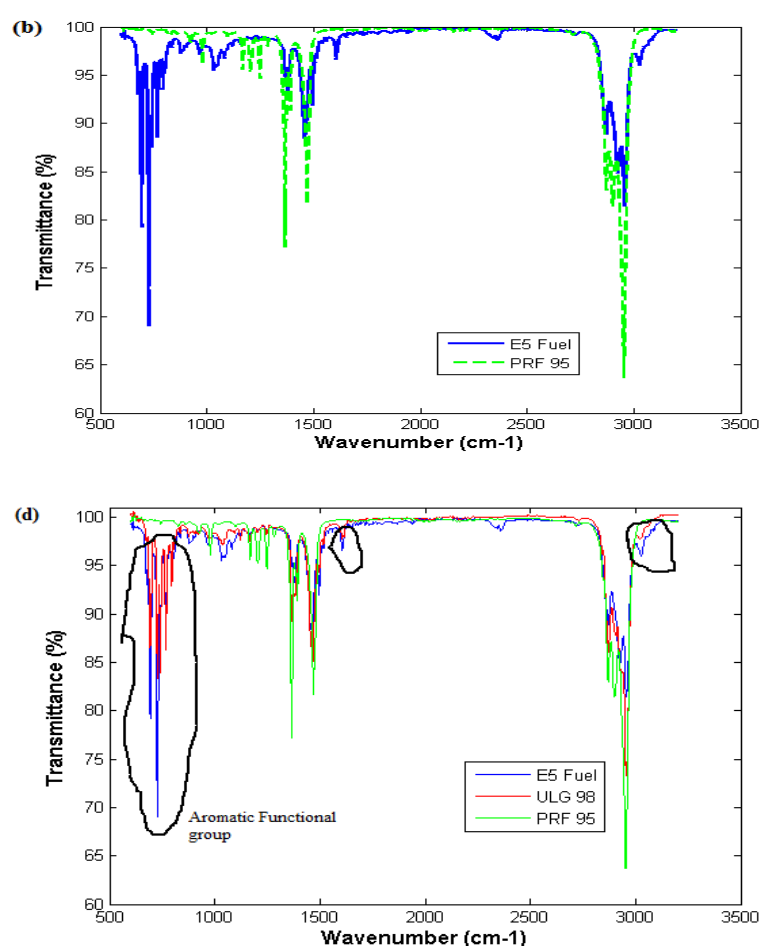


\section{ACKNOWLEDGEMENT}

This research was made possible through the financial sponsorship from Petroleum Technology Development Fund (PTDF) through the scholarship award, PTDF/ED/L.LANDMARK/UDC/PHD/013/12.

\section{REFERENCES}

[1] Mittal V., Revier B. M. and Heywood J. B. "Phenomena that Determine Knock Onset in SparkIgnition Engines", SAE Technical Paper, 2007-010007, 2007, pp1-11.

[2] Conway Graham T. Cyclic Variability of Flame Propagation and Autoignition in Supercharged and Naturally Aspirated SI Engines, $\mathrm{PhD}$ Thesis in the School of Mechanical Engineering, University of Leeds, U.K., 2013.

[3] Hill, P. G. and Zhang, D. "The Effects of Swirl and Tumble on Combustion in Spark-Ignition Engines", Prog. Energy Combust. Sci., Vol. 20, 1994, pp. 373429.

[4] Kang K. Y. and Back J. H. "Turbulence Characteristics of Tumble Flow in a Four-Valve Engine", Experimental Thermal and Fluid Science, Vol. 18, pp 231 - 243. 1998,

[5] Heywood J. B. Internal Combustion Engine Fundamentals, McGraw-Hill Series in Mechanical Engineering, McGraw-Hill, Inc., 1988.

[6] Brown N. M. Characterisation of Emissions and Combustion Stability of a Port Fuelled Spark Ignition Engine, University of Nottingham, PhD thesis, 2009.

[7] Hussin, A. New and Renewable Energy: Renewable Fuels in Internal Combustion Engines, PhD Thesis, Department of Mechanical Engineering, University of Leeds, 2012.

[8] Bardin, "Technical aspect of Ethyl Tert-Butyl Ether (ETBE) for Large-Scale Use as Gasoline Improver", Energy Technology, Wiley Online Library, Vol.2, , pp. $194-204.2014$

[9] William H., "How Superchargers Work" http://auto.howstuffworks.com/supercharger1.ht m. Accessed on December 20, 2016.

[10] Jegs."Everything You Want to Know About Superchargers", $\quad$ http://www.jegs.com/techarticles/superchargers.html. Accessed on December 20, 2016.

[11] Severson A. "The Basics of Turbocharging and Supercharging",

http://ateupwithmotor.com/terms-technologydefinitions/turbocharging-and-supercharging/. Accessed on December 20, 2016.

[12] Roberts Philip J. Fuel and Residual Effect in Spark Ignition and Homogeneous Charge Compression Ignition Engines, School of Mechanical engineering,
University of Leeds, United Kingdom, PhD Thesis, 2010.

[13] Horner Thomas G. "Engine Knock Detection using Spectral Analysis Technique with a TMS320 DSP", Application Report for Texas Instrument, August, 1995.

[14] Hattrell Timothy $A$ Computational and Experimental Study of Spark Ignition Engine Combustion, School of Mechanical Engineering, University of Leeds, PhD thesis, 2007.

[15] Revier B. M. Phenomena that Deternines Knock Onset in Spark-Ignited Engines, MSc Thesis. Department of Mechanical Engineering. Massachusetts Institute of Technology, United States, pp 11-15. 2006,

[16] Holtti Janne Tuning Light Knock Limits on SG Engines, A Bachelor's Thesis, Department of Electrical Engineering, University of Applied Science, Novia, 2012.

[17] Höglund Filip Knock Detection in a Two-Stroke Engine to be Used in the Engine Management System, a Master's Thesis in the Institutionen för systemteknik, Department of Electrical Engineering , Linköpings universitet, Linköpings, Sweden, 2014.

[18] Pan, J. and Sheppard, C.G.W. "A Theoritical and Experimental Study of the Modes of End Gas Autoignition Leading to Knock in S.I. Engines", $S A E$ Technical Paper, 942060, 1994.

[19] Lee, J., Hwang, S., Lim, J. "A New Knock -Detection Method using Cylinder pressure, Block Vibration and Sound Pressure Signal from a SI Engine", SAE Technical Paper, 981436, 1998.

[20] Brunt M. F. J., Pond C. R. and Biundo J. "Gasoline Engine Knock Analysis Using Cylinder Pressure Data", SAE Technical Paper, 980896, International Congress and Exposition, Detroit, Michigan, , pp116. 1998.

[21] Piernikarski D., Hunicz J., Komsta H. "Detection of Knocking Combustion in a Spark Ignition Engine Using Optical Signal from the Combustion Chamber", Eksploatacia I Niezawodnosc Maintenance and Reliability, Vol. 15, , pp $214-220$. 2013.

[22] Coates J. Interpretation of Infrared Spectra, A Practical Approach, Encyclopedia of Analytical Chemistry R.A. Meyers (Ed.),2000, pp10815 10837.

[23] Larkin, P. Infrared and Raman Spectroscopy; Principles and Spectral Interpretation, $1^{\text {st }}$ Ed., Elsevier, 2011.

[24] Stuart B. Infrared Spectroscopy: Fundamentals and Applications, John Wiley \& Sons, Ltd., 2004. 


\section{APPENDIX A}

\%A Program to Detect Knocking Cycles

clear all; close all; clc;

$A=\operatorname{load}($ 'fir98tot13.txt'); \%Load text file

[row col] $=\operatorname{size}(A)$;

$\%$ Processing the Knock Intensity with Cycles, Angles and

Intensities

for $\mathrm{i}=1$ : $\mathrm{col}$

$\mathrm{A} 1=\mathrm{A}(:, \mathrm{i})$;

fs $=22500$;

time $=(1 / \mathrm{fs})^{*}$ length $(\mathrm{A} 1)$;

$t=$ linspace $(0$, time,length $(A 1))$;

$\mathrm{L}=$ length $(\mathrm{A} 1)$;

$\mathrm{fc}_{\mathrm{C}}=5000 ; \%$ Cutoff frequency

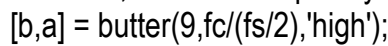

$Y=$ filtfilt $(b, a, A 1)$;

Pmax_Y(i) $=\max (Y)$;

if Pmax_Y(i)>=1\%bar (Sum of negative \& positive values $=2$ bar)

$Y \max (i)=(\text { find }(Y==P \max Y Y(i)))^{*} 0.2$;

PmaxG(i) = Pmax_Y(i);

$A x(i)=i$;

end

$x=(-899: 1: 900)^{*} 0.2$;

crank encoder to crank

figure(i), $\operatorname{plot}(x, Y)$

$\%$ Conversion of pulses from the

\section{\%angles}

end

$Z=\left[A x^{\prime}((Y \max )-180)^{\prime}(\right.$ PmaxG)'];

$\%$ sorting the Knock Cycles into a Matrix

$c=$ find $(Z(:, 1)>0)$;

$\mathrm{Z} 1=[\mathrm{Z}(\mathrm{c}, 1:$ end $)]$

$\%$ Plot

plot(Z1(:,2),Z1(:,3),'b*')

ylabel('Knock Intensity (Bar)');

xlabel('Crank Angle aTDC');

Title('RON 98 13bTDC')

$\%$ Saving Data

save('KI_13btdc.txt','Z1','-ascii')

\section{APPENDIX B}

$\%$ A Program to Sort the Knocking Cycles in theFast, Medium and Slow Cycles

clear all; close all; clc;

$A=\operatorname{load}($ 'isoooct13btdc.txt'); \% Loading pressure data file

[row col] $=\operatorname{size}(A)$;

$\max \_p=\max (A)$;

mean_max_pres $=$ mean $\left(\max \_p\right)$;

Std_max_pres $=\operatorname{std}\left(\max \_p\right)$;

upper_mean_max_pres = mean_max_pres + Std_max_pres

lower_mean_max_pres = mean_max_pres - Std_max_pres;

$\%$ Processing the Knock Intensity with Cycles, Angles and

Intensities

for $\mathrm{i}=1: \mathrm{col}$

$\mathrm{A} 1=\mathrm{A}(:, \mathrm{i})$;

fs $=22500$;

time $=(1 / \mathrm{fs})^{*}$ length $(\mathrm{A} 1)$;

$\mathrm{t}=$ linspace $(0$, time,length $(\mathrm{A} 1))$;
$\mathrm{L}=$ length $(\mathrm{A} 1)$;

$\mathrm{fc}=5000 ; \quad \%$ Cut-off frequency

$[\mathrm{b}, \mathrm{a}]=\operatorname{butter}\left(9, \mathrm{fc} /(\mathrm{fs} / 2)\right.$, 'high'); $^{\prime}$

$Y=$ filtfilt(b,a,A1);

Pmax_Y(i) $=\max (Y)$;

if Pmax_Y(i)>=1 \%bar (Sum of negative $\&$ positive values $=2 \mathrm{Bar}$ )

$Y \max (i)=\left(\text { find }\left(Y==P \max \_Y(i)\right)\right)^{*} 0.2$;

$P \max (i)=$ Pmax_Y(i);

$A x(i)=i$;

end

$\mathrm{x}=(-899: 1: 900)^{*} 0.2$

end

$Z=[$ Ax' ((Ymax)-180)' (PmaxG)'];

$\%$ sorting the Knock Cycles into a Matrix

$c=$ find $(Z(:, 1)>0)$;

$\mathrm{Z} 1=[\mathrm{Z}(\mathrm{c}, 1: \mathrm{end})]$

figure(300)

$\operatorname{plot}\left(Z 1(:, 2), Z 1(:, 3), b^{* \prime}\right)$

ylabel('Knock Intensity (bar)');

xlabel('Crank Angle aTDC');

Title('Iso Octane 13bTDC')

\%Fast, Medium and Slow Cycles

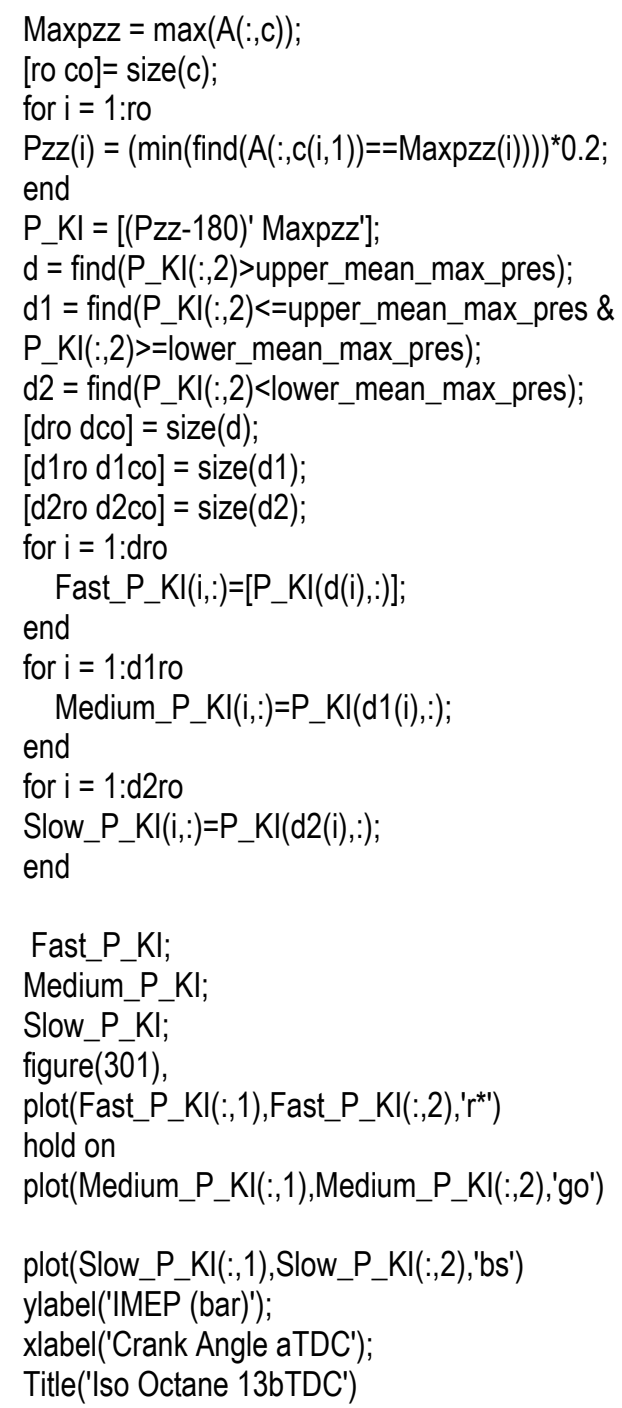

